\title{
CABARAN YANG DIHADAPI OLEH GURU DALAM PELAKSANAAN PERSEKITARAN PEMBELAJARAN MAYA FROG DI BILIK DARJAH
}

\section{(TEACHERS' CHALLENGES IN THE IMPLEMENTATION OF FROG VIRTUAL LEARNING ENVIRONMENT IN THE CLASSROOMS)}

\author{
Hasliza Hashim, Siti Munira Mohd Nasri and Zarina Mustafa* \\ School of Educational Studies, Universiti Sains Malaysia. \\ 11800 Pulau Pinang, Malaysia \\ *Corresponding author: mzarina@usm.my
}

Published date: 20 January 2017

To cite this article: Hasliza Hashim, Siti Munira Mohd Nasri, \& Zarina Mustafa. (2016). Cabaran yang dihadapi oleh guru dalam pelaksanaan persekitaran pembelajaran maya frog di bilik darjah. Asia Pacific Journal of Educators and Education, 31, 115-129. http://dx.doi.org/10.21315/apjee2016.31.7

To link to this article: http://dx.doi.org/10.21315/apjee2016.31.7

\begin{abstract}
Abstrak: Kajian ini dijalankan untuk mengenalpasti cabaran yang dihadapi oleh guru dalam pelaksanaan Persekitaran Pembelajaran Maya ataupun lebih dikenali sebagai Frog Virtual Learning Environment (VLE) di bilik darjah. Kajian berpendekatan kualitatif ini menggunakan teknik in-depth interview untuk mengumpul data. Dengan menggunakan persampelan bertujuan, lapan orang guru telah ditemu bual menggunakan protokol temubual Levels of Use Interview Schedule (LoU-IS) yang telah diubahsuai untuk mendapatkan maklumat berkaitan dengan cabaran yang mereka hadapi dalam penggunaan Frog VLE. Dapatan kajian menunjukkan antara cabaran yang dihadapi oleh guru dalam pelaksanaan Frog VLE ini adalah: kekangan infrastruktur; kekangan masa; inisiatif guru; efikasi kendiri guru; serta integriti dan sikap guru terhadap Frog VLE.
\end{abstract}

Kata kunci: Cabaran, Frog VLE, sistem pengajaran dan pembelajaran (PdP)

\begin{abstract}
The main purpose of the study was to identify teachers' encountered challenges in the implementation of Frog Virtual Learning Environment (VLE) in the classrooms. This qualitative study employed the in-depth interview method for data collection. A purposive sampling of eight teachers were interviewed. An adapted Level of Use Interview Schedule (LoU-IS) was used as the instrument to elicit information on the
\end{abstract}


challenges which teachers encountered in the implementation of Frog VLE. The findings show that the encountered challenges include infrastructural constraints; time constraints; teachers' initiatives; teachers' self efficacy; and teachers' integrity and attitude toward Frog VLE.

Keywords: Challenges, Frog Virtual Learning Environment (VLE), PdP

\section{PENGENALAN}

Persekitaran Pembelajaran Maya Frog ataupun lebih dikenali sebagai Frog Virtual Learning Environment (VLE) adalah satu inovasi baharu yang digunakan untuk mewujudkan persekitaran yang efisyen untuk guru, ibu bapa dan pelajar khususnya. Frog VLE merupakan satu projek yang dilaksanakan bersama 1BestariNet. 1BestariNet ialah capaian internet yang dibekalkan oleh YTL Yes Network dan ianya merupakan satu projek usahasama di antara pihak Kementerian Pendidikan Malaysia (KPM) dengan syarikat telekomunikasi YTL. Kemudahan Frog VLE ini dibangunkan secara berperingkat mulai Disember 2011. Dijangkakan sepuluh ribu sekolah rendah dan menengah di seluruh negara akan dilengkapi dengan akses Internet 4G dan VLE pada penghujung tahun 2013.

Frog VLE yang diperkenalkan di sekolah di Malaysia adalah satu sistem pengajaran dan pembelajaran (PdP) berasaskan web yang menyerupai dunia pembelajaran sebenar. Sistem ini mengintegrasikan konsep pendidikan konvensional dengan kaedah maya yang mana ia dapat memberi manfaat kepada guru, pelajar, pentadbir sekolah, dan juga ibu bapa.

Dengan Frog VLE, guru mampu memudahkan proses PdP mereka. Mereka dapat menyampaikan pengajaran dengan pendekatan yang lebih menyeronokkan, memberi tugasan kepada pelajar serta berhubung dengan mereka secara dalam talian. Guru juga dapat berkolaborasi bersama staf pentadbiran serta mendapatkan maklumat terkini mengenai sekolah secara dalam talian.

Frog VLE juga merupakan platform berteraskan cloud yang fleksibel dan boleh diakses di mana-mana, sama ada dari dalam sekolah mahupun di luar kawasan sekolah. Selain itu, fail dan data yang disimpan di cloud boleh diakses di manamana sahaja dan bila-bila masa melalui capaian internet (Kementerian Pendidikan Malaysia, 2012).

Fungsi utama Frog VLE ini adalah sebagai bahan PdP interaktif di antara guru dan pelajar. Frog VLE ini juga menjadi satu pengantar penyampaian maklumat yang berkesan kepada warga sekolah di mana ianya dapat menghantar dan menerima maklumat menerusi emel. Maklumat dapat disampaikan secara mudah 
dan pantas serta mudah diakses dari pelbagai sumber. Maklumat juga mudah diurus dan dikemaskini. Justeru, pengurusan sekolah akan menjadi lebih teratur.

Setiap sekolah akan menerima akses VLE selepas satu latihan penggunaan Frog VLE diberikan kepada setiap guru dan pelajar. Penggunaan VLE dalam PdP di sekolah di negara ini boleh dikatakan masih baru dipraktikkan walaupun sistem VLE ini sudah lama diguna pakai di peringkat tertiari.

Pada tahun 2014, kumpulan sasaran pertama bagi pelaksanaan Frog VLE ini adalah guru. Tidak dapat dinafikan kursus berkaitan penggunaan VLE yang dikendalikan untuk membimbing para guru pada ketika ini amat terhad sedangkan pelaksanaannya melibatkan semua guru di bawah KPM. Oleh itu, tujuan kajian ini dijalankan adalah untuk mengenal pasti cabaran yang dihadapi oleh guru dalam pelaksanaan Frog VLE dalam PdP di bilik darjah.

\section{KEPENTINGAN KAJIAN}

Guru merupakan tulang belakang dalam usaha melahirkan modal insan yang berpengetahuan, berkemahiran tinggi, kreatif, inovatif dan berdaya saing. Untuk menjadi seorang guru yang proaktif, guru perlu bersedia dari segi mental dan fizikal untuk menempuh sebarang kebarangkalian perubahan. Guru juga perlu menyesuaikan diri mereka dengan pendekatan serta kaedah penyampaian ilmu yang berkesan serta mesra pelajar, sesuai dengan kaedah semasa. Frog VLE ini adalah satu daripada pendekatan yang baharu diperkenalkan, sesuai dengan peredaran perubahan kurikulum ke arah era Teknologi Maklumat dan Komunikasi (TMK). Kajian ini akan memberi gambaran tentang cabaran yang dihadapi oleh guru terhadap pelaksanaan Frog VLE dalam proses PdP yang sangat berhubung rapat dengan profesion mereka.

Selain daripada guru, kajian tentang pelaksanaan Frog VLE ini juga akan memberi kesan kepada pelajar. Pada tahun 2015, kumpulan sasaran bagi pelaksanaan Frog VLE adalah pelajar. Melalui Frog VLE, pelajar boleh merujuk pada paparan maya pada bila-bila masa dan di mana-mana sahaja berbanding dengan kaedah tradisional dan konvensional di mana guru dan pelajar terikat pada had waktu dalam jadual pembelajaran harian. Perkongsian ilmu dalam bentuk komunikasi dua hala dengan rakan yang lain juga dapat mengasah minat serta meningkatkan keyakinan pelajar.

Pada tahun 2016 pula, kumpulan sasaran bagi pelaksanaan Frog VLE ini adalah dari kalangan ibu bapa. Ibu bapa juga merupakan individu berkepentingan yang terlibat dalam pelaksanaan Frog VLE ini. Antara kelebihan Frog VLE kepada ibu 
bapa ialah mereka dapat mengikuti perkembangan pelbagai aktiviti atau program yang dianjurkan oleh pihak sekolah. Selain itu, ibu bapa juga dapat melihat laporan mesyuarat Persatuan Ibu Bapa dan Guru (PIBG) yang disediakan, sama ada mereka hadir ataupun tidak hadir pada hari tersebut. Dari situ mereka samasama akan dapat mengetahui tentang apa-apa keputusan yang telah diambil ketika mesyuarat PIBG itu dijalankan.

Selain itu, dapatan kajian ini juga diharapkan dapat membantu pihak sekolah untuk mengenal pasti kemudahan dan keperluan guru bagi melaksanakan PdP secara maya. Dapatan kajian ini juga dapat membantu pihak pentadbir sekolah, Bahagian Perkembangan Kurikulum (BPK), Jabatan Pendidikan Negeri (JPN), dan Pejabat Pendidikan Daerah (PPD) dalam menyediakan kemudahan yang diperlukan guru dalam pelaksanaan Frog VLE ini. Akhir sekali, dapatan kajian ini juga dapat menjadi rujukan kepada pengkaji lain tentang pelaksanaan Frog VLE di Malaysia.

\section{RASIONAL KAJIAN}

Johari dan Fazliana (2011) mendapati bahawa ramai guru yang mengalami masalah dalam penggunaan aktiviti berbantukan teknologi dalam proses PdP di bilik darjah. Sebagai penerima inovasi, guru tentunya mempunyai pelbagai alasan yang menjadikannya sebagai cabaran dalam pelaksanaan PdP secara maya ini. Menyedari hakikat bahawa penggunaan TMK khususunya pembelajaran maya telah berkembang pesat dalam proses PdP, guru sewajarnya melakukan anjakan paradigma ke arah mindset tersebut.

Dalam era mutakhir ini, penggunaan kaedah tradisional sudah dianggap kurang berkesan dan tidak menggamit minat generasi baru untuk belajar, terutamanya bagi mata pelajaran yang melibatkan pembacaan, sebagai contohnya mata pelajaran Sejarah. Justeru, para pendidik perlu memikirkan kaedah alternatif yang lebih inovatif dan efektif, seperti pembelajaran yang berasaskan TMK, khasnya VLE. Ianya bersesuaian dengan peranan pendidik masa kini yang mengalami transformasi daripada seorang pembawa dan penyalur maklumat kepada seorang pengurus, jurulatih dan fasilitator (Zarina, 2010). 


\section{METODOLOGI}

\section{Sampel Kajian}

Persampelan bertujuan telah digunakan di mana lapan orang guru sekolah menengah telah dipilih sebagai responden untuk in-depth interview. Mereka dipilih berdasarkan lingkungan umur (age range), latar belakang pendidikan, pengalaman mengajar, dan tahap kemahiran TMK mereka.

\section{Tatacara In-depth Interview}

Bagi sesi in-depth interview ini, protokol temu bual yang telah diadaptasikan dari Levels of Use Interview Schedule (LoU-IS) dari Loucks, Newlove and Hall (1975) yang dipetik dari Zarina (2012) telah digunakan bagi mendapatkan maklumat yang diperlukan untuk dapatan kajian. Pengkaji telah memilih guru yang terlibat sebagai responden setelah mengenal pasti latar belakang responden serta pengkaji telah terlebih dahulu memohon kebenaran responden untuk ditemu bual. Sesi temu bual dijalankan mengikut kesesuaian dan keselesaan responden memandangkan tiada penetapan masa ditentukan bagi menemu bual setiap responden.

Setiap responden yang ditemu bual telah disoal tentang cabaran yang mereka hadapi dalam pelaksanaan Frog VLE dalam PdP mereka. Penekanan dan perkara yang ingin dikenal pasti dalam sesi temu bual ini adalah merujuk kepada cabaran guru semasa menggunakan Frog VLE dalam PdP. Responden juga diberi peluang untuk berkongsi pengalaman mereka tentang kebaikan dan kelemahan menggunakan Frog VLE dalam proses PdP. Pengalaman yang dikongsi tersebut juga akan menentukan keberkesanan penggunaan Frog VLE dalam proses PdP di sekolah. Pengkaji juga telah mengupas dan mengenal pasti masalah ini dengan lebih mendalam untuk mengetahui mengapa perkara atau trend ini berlaku.

Semasa sesi menemu bual, catatan diperlukan di mana transkrip dalam bentuk bertulis dan catatan direkod secara audio supaya transkrip dapat dihasilkan dan dianalisis untuk mendapatkan data kajian.

\section{Analisis Data Kualitatif}

Data kualitatif dikumpul melalui kaedah in-depth interview yang dijalankan untuk mengenal pasti cabaran yang dihadapi oleh guru dalam pelaksanaan Frog VLE dalam PdP. Analisis kandungan tematik berdasarkan transkrip temu bual ini telah dapat mengenal pasti cabaran yang dihadapi oleh guru. Data dari sesi temu 
bual yang dijalankan oleh pengkaji merupakan data yang lebih khusus dan mendalam berkenaan dengan isu penting yang dikaji.

\section{PERBINCANGAN DAPATAN KAJIAN}

Perbincangan dapatan kajian tentang cabaran guru dalam pelaksanaan Frog VLE ini dapat dirumuskan seperti berikut.

\section{Kekangan Infrastruktur}

Hasil daripada temu bual mendapati bahawa di antara cabaran yang dihadapi oleh guru semasa menggunakan Frog VLE dalam PdP adalah kekangan dari aspek infrastruktur. Senario kekurangan atau kelemahan dari aspek infrastruktur ini merupakan fenomena yang sering dialami dalam mengaplikasikan penggunaan TMK dalam proses PdP.

Cabaran dari segi kemudahan infrastruktur yang tidak mencukupi ini turut disokong oleh Bayrei (2008) dan Dnyaneshwar (2011). Menurut mereka, proses pengintegrasian teknologi maklumat dalam PdP memerlukan prasarana yang mencukupi seperti kemudahan makmal komputer, peralatan berkaitan dengan penggunaan teknologi maklumat, serta penyediaan dan penyelenggaraan komputer yang mencukupi dan lancar. Dari dapatan temu bual, responden berpendapat sistem penyelenggaraan bahan teknologi maklumat di sekolah yang tidak cekap menjadi salah satu punca permasalahan pengintegrasian ini tidak dapat dilaksanakan dengan baik. Bantuan teknikal untuk mengekal dan menggunakan sumber teknologi sangat penting dalam memaksimumkan penggunaan teknologi dalam pembelajaran.

Menurut responden lagi, cabaran dari aspek kekangan infrastruktur dilihat sebagai cabaran utama dalam melaksanakan PdP melalui Frog VLE ini. PdP melalui Frog VLE memerlukan peralatan dan perkakasan yang lengkap seperti komputer yang mencukupi mengikut jumlah pelajar bagi setiap kelas dan akses kepada internet yang berkelajuan tinggi. Masalah akan wujud apabila prasarana yang tidak mencukupi menyebabkan terdapat ramai pelajar yang tidak dapat turut serta dalam proses PdP melalui Frog VLE ini. Tambahan pula, adakalanya prasarana yang telah sedia ada pula rosak dan tidak dapat digantikan kerana melibatkan isu peruntukan.

Selain itu, responden juga menyatakan di antara kekangan berkaitan yang dihadapi dalam pelaksanaan pembelajaran maya ini adalah berlakunya ketidakseimbangan dalam pengagihan komputer di antara sekolah bandar dengan 
sekolah di luar bandar. Ini secara tidak langsung menyebabkan wujudnya jurang pendidikan di antara pelajar di kawasan bandar dan pelajar di kawasan luar bandar. Di samping itu, walaupun pembelajaran melalui Frog VLE ini boleh dijalankan di mana-mana sahaja, namun, masalah masih lagi wujud kerana tidak semua pelajar mempunyai komputer meja ataupun komputer riba yang dilengkapi dengan kemudahan internet di rumah. Oleh itu, guru masih lagi mempunyai masalah untuk melaksanakan PdP secara maya ini.

Tambahan lagi, para pelajar dan guru mungkin menghadapi beberapa masalah teknikal di sekolah, di antaranya seperti kegagalan elektrik, capaian internet, serta masalah dalam kelajuan sambungan internet. Walaupun telah dilengkapi dengan akses internet berkelajuan tinggi 4G, ia masih belum mencukupi untuk membekalkan capaian internet yang terbaik bagi setiap sekolah di seluruh negara. Oleh itu, masalah ini masih lagi berlaku melainkan guru menggunakan internet peribadi seperti internet broadband dan hot spot.

Menurut responden lagi, apabila guru merancang untuk sesuatu proses PdP yang menggunakan alatan teknologi, alatan teknologi itu perlu disediakan dan ia perlu berada dalam keadaan yang baik. Namun, teknologi pula merupakan satu komoditi yang masih tidak stabil. Responden yang ditemu bual menyatakan bahawa mereka mempunyai masalah dalam menggunakan Frog VLE kerana sistem Frog VLE itu sendiri masih belum berfungsi sepenuhnya dan masih lagi dalam proses penambahbaikan. Seseorang guru akan berasa kurang bersemangat sekiranya kemudahan teknologi yang ingin digunakan tidak disediakan dengan baik. McKenzie (1999) dan Al-Bataineh dan Brooks (2003) juga bersependapat dalam hal ini.

\section{Kekangan Masa}

Dari dapatan temu bual, satu lagi cabaran yang dihadapi oleh guru adalah kekangan masa, yakni yang melibatkan aspek masa yang tidak mencukupi. Para responden beranggapan pembelajaran melalui Frog VLE hanya membuang masa sedangkan mereka mempunyai beban tugas lain yang lebih penting untuk diberikan perhatian. Ini disebabkan terdapat halangan seperti capaian internet rendah yang memakan masa lalu membantutkan usaha guru untuk menggunakannya.

Selain itu, terdapat juga responden yang menyatakan bahawa guru memerlukan masa bagi mempelajari dan mengaplikasi Frog VLE di dalam bilik darjah. Walaupun telah diberi latihan dalaman di peringkat sekolah, namun ianya masih belum mencukupi terutamanya bagi guru yang kurang berkemahiran TMK. Mereka memerlukan masa yang agak lama untuk menyesuaikan diri mereka 
dengan pendekatan baharu ini. Ini adalah kerana Frog VLE merupakan satu inovasi teknologi baharu yang memerlukan pemahaman yang lebih teliti dan penguasaan yang jitu. Pandangan ini turut disokong oleh Norazilawati, Noraini, Nik Azmah dan Rosnidar (2013).

Posey, Burgess, Eason dan Jones (2010) menyatakan bahawa guru merupakan individu yang mempunyai beban tugas yang berat dan mereka tidak mempunyai masa untuk memikirkan perkara yang tidak mempunyai kaitan dengan profesion mereka. Kebanyakan responden yang ditemu bual merasakan pelaksanaan Frog VLE ini hanya membuang masa kerana mereka dibebani pelbagai tugas lain yang perlu diselesaikan. Selain itu, peruntukan masa bagi setiap minggu pengajaran hanya cukup untuk mereka menghabiskan silibus yang telah ditetapkan dalam sistem pendidikan negara. Jadi, untuk mereka meneroka dan mengaplikasikan Frog VLE dalam proses PdP adalah sesuatu yang agak merumitkan bagi mereka.

\section{Efikasi Kendiri Guru}

Berdasarkan hasil daripada temu bual yang dijalankan, beberapa orang responden menyatakan bahawa salah satu cabaran lagi dalam penggunaan Frog VLE dalam proses PdP adalah efikasi kendiri atau kepercayaan diri yang rendah. Efikasi kendiri merupakan keyakinan seseorang terhadap kebolehannya untuk melaksanakan sesuatu tingkah laku yang dikehendaki dengan jayanya (Bandura, 1977, dipetik daripada Fadhilah, 2013). Efikasi kendiri guru atau kebolehan mereka untuk bekerja secara berkesan dengan TMK merupakan perkara faktor penting dalam menentukan corak penggunaan TMK. Responden berpendapat seorang guru yang mempunyai keyakinan diri yang rendah terhadap penggunaan Frog VLE akan menyebabkan mereka kurang berminat untuk mengaplikasikannya dalam PdP. Guru yang mempunyai tahap efikasi yang rendah juga kurang berminat untuk belajar dan meneroka tentang penggunaan Frog VLE. Ini adalah kerana mereka mempunyai perasaan resah atau computer anxiety serta akan sentiasa teragak-agak untuk menggunakan inovasi teknologi tersebut dalam PdP. Oleh itu, kata putus untuk menggunakan Frog VLE di bilik darjah atau di sekolah juga sangat dipengaruhi oleh efikasi kendiri guru.

Menurut responden lagi, tahap efikasi kendiri guru terhadap pengaplikasian Frog VLE dalam PdP juga diukur melalui kemahiran komputer dan TMK seseorang guru, di samping mengambil kira faktor umur guru tersebut. Dengan kata lain, efikasi kendiri guru adalah keupayaan guru untuk menggunakan Frog VLE secara berkesan sekaligus mempengaruhi corak PdP di bilik darjah. 


\section{Inisiatif Guru}

Hasil dari temu bual juga mendapati bahawa kemahiran TMK dalam kalangan guru juga merupakan cabaran yang perlu dihadapi dalam pelaksanaan Frog VLE dalam proses PdP. Penggunaan TMK dalam PdP bermaksud menggunakan TMK secara terancang dan bersesuaian untuk meningkatkan kecekapan proses serta keberkesanan proses PdP (Kementerian Pendidikan Malaysia, 2012).

Menurut responden, cabaran untuk mengintegrasikan TMK dalam PdP pada semua peringkat persekolahan kini semakin mendesak kerana penggunaan pelbagai sistem dalam talian semakin rancak digunakan di sekolah, termasuklah Frog VLE. Masih terdapat guru yang kurang mengintegrasikan TMK dalam PdP. Terdapat juga guru yang masih belum mahir dalam mengakses portal, menyediakan bahan pengajaran dan memproses maklumat melalui laman web. Mereka juga tidak mempunyai kemahiran untuk mengendali dan memanipulasi sesuatu alat. Selain dari itu, kelancaran penyampaian isi pengajaran juga akan terganggu dan menjadi tidak berkesan. Ini akan menyebabkan masalah dalam usaha untuk menjadikan Frog VLE sebagai satu pengantar pengajaran yang melibatkan semua guru dan pelajar.

Responden berpendapat dalam sesuatu sesi pembelajaran, guru seringkali berhadapan dengan pelajar yang berbeza tahap dari segi kebolehan dan pencapaian. Keadaan ini memerlukan kepakaran guru dalam menentukan strategi PdP, menentukan pendekatan, memilih kaedah dan menetapkan teknik tertentu yang sesuai dengan perkembangan dan kebolehan pelajar. Strategi yang dipilih itu mestilah dapat merangsang pelajar secara aktif dan mampu membantu pelajar memahami konsep dengan jelas. Ini bukan sahaja dapat menarik minat pelajar malah dapat menghasilkan satu pembelajaran yang bermakna. Begitu juga cabarannya dalam penggunaan Frog VLE dalam PdP. Bagi guru untuk memuat turun bahan di laman pembelajaran secara maya dalam Frog VLE yang dapat memenuhi semua kriteria yang disebutkan ternyata bukan satu kerja yang mudah. Yang tampak pasti, ini adalah satu lagi tugasan sampingan bagi mereka selain daripada aktiviti mengajar di dalam kelas.

Responden juga tidak menafikan bahawa penggunaan aplikasi Frog VLE ini dapat membantu PdP. Guru dapat berinteraksi dengan pelajar secara maya dan dapat berkongsi pelbagai input pembelajaran yang dapat dimuat turun dan dipaparkan dalam laman. Namun begitu, guru juga mempunyai komitmen lain apabila berada di luar waktu persekolahan. Maka, kemampuan guru untuk memuat turun dan mencari bahan pembelajaran untuk dikongsi dalam laman adalah terhad. 
Di samping itu, tumpuan juga harus diberikan terhadap kemudahan guru untuk menggunakan internet, terutamanya di luar waktu persekolahan. Hal ini kerana dalam mengaplikasikan Frog VLE untuk PdP, kemudahan internet perlu diaktifkan sepanjang masa. Selain melibatkan kos yang tinggi, capaian internet juga berbeza-beza mengikut lokasi.

Wan Abdul Halim, Nor Laila dan Shafie (2006) menyatakan guru yang ideal adalah mereka yang berpengetahuan tinggi, mahir dalam bidang teknikal dan cekap menjalankan tugas sebagai seorang guru. Pengajaran yang berkesan memerlukan kemahiran dan pengetahuan yang luas terhadap mata pelajaran serta mempunyai kefahaman terhadap aspek pembelajaran pelajar. Ini jelas menunjukkan bahawa guru bukan sahaja perlu menguasai kandungan pembelajaran tetapi perlu juga merancang bahan pembelajaran yang ingin dimuat turun dan dikongsi bersama guru lain dan pelajar di dalam aplikasi Frog VLE ini.

Dapatan dari temu bual yang dijalankan juga mendapati adanya segelintir guru, terutamanya guru yang lebih senior, tidak mempunyai kemahiran yang tinggi dalam penggunaan Frog VLE. Kemahiran yang rendah akan menyukarkan lagi pengaplikasian terhadap inovasi baharu tersebut. Dalam mengaplikasikan Frog VLE di sekolah, guru harus mengetahui dan memahami setiap fungsi ikon dalam widgets dan tahu mengendalikan dashboard tersebut sehingga dapat mewujudkan laman sendiri serta boleh dikongsi dengan guru lain dan pelajar.

Norazila (2008) dalam kajiannya mendapati di antara faktor yang mempengaruhi guru dalam penggunaan teknologi dalam pengajaran adalah latar belakang guru, sikap dan keprihatinan guru. Guru yang mempunyai lebih pengetahuan dalam komputer menunjukkan sikap lebih positif terhadap penggunaan komputer dalam pengajaran. Sebaliknya, guru yang kurang berpengetahuan harus menyedari bahawa mereka harus mendalami serta mengasah ilmu dan kemahiran mereka dalam menggunakan teknologi di dalam kelas.

Dalam konteks pendidikan, kemahiran ini merujuk kepada kemahiran guru di dalam bilik darjah. Kemahiran yang perlu dimiliki oleh setiap guru adalah kemahiran belajar, kemahiran berfikir, kemahiran merancang, kemahiran pemudahcaraan, kemahiran berkomunikasi dan kemahiran mengurus (Zarina, 2012). Begitu juga dalam aplikasi Frog VLE ini, responden berpandangan guru perlu mengurus laman web mereka sendiri, merancang pembelajaran, dan berkomunikasi dengan pelajar pada bila-bila masa dengan menggunakan teknologi yang sedia ada. Dari itu, guru harus peka terhadap perubahan yang berlaku dalam pendidikan. Guru bertanggungjawab untuk membina daya pemikiran yang analitikal, kritis dan kreatif terhadap pelajar. Pelajar diajar agar dapat menyesuaikan diri dengan perubahan yang berlaku di sekeliling mereka. 
Oleh itu, guru sendiri harus mempunyai inisiatif untuk menguasai kemahiran dan pengetahuan yang terkini demi menjalankan tugas.

\section{Integriti dan Sikap Guru terhadap Frog VLE}

Menurut responden, dalam pelaksanaan Frog VLE, kualiti profesional dan nilai sosial yang baik itu penting. Kualiti PdP serta nilai sosial seseorang guru itu boleh dinilai melalui bahan yang dimuat turun dan dikongsi dalam dashboard atau lamannya. Melalui aplikasi Frog VLE, cabaran yang perlu dilalui oleh guru adalah mereka perlu lebih sabar dalam mengendalikannya kerana pengaplikasian Frog VLE bergantung kepada kelajuan internet.

Terdapat juga responden yang menyuarakan pandangan mereka bahawa satu lagi cabaran dalam pelaksanaan Frog VLE ialah kurangnya kerjasama antara rakan sekerja terhadap penggunaan inovasi ini. Mereka berpendapat, kerjasama yang kurang antara rakan sekerja akan menyukarkan guru untuk menggunakan Frog VLE. Seseorang guru itu perlulah sentiasa bekerjasama dengan rakan sejawat yang lain kerana kemajuan pelajaran dan pendidikan pelajar di sekolah bergantung kepada kerjasama dan muafakat di antara semua golongan guru di sekolah itu. Dalam mengendalikan aplikasi Frog VLE, kerjasama antara guru dapat dilihat apabila mereka sama-sama membantu dalam menyediakan satu laman web pembelajaran. Guru yang lebih pakar dalam bidang pengkomputeran boleh menjadi fasilitator kepada rakan guru yang lain, sama ada sewaktu bengkel dalaman mahupun secara tidak langsung seperti semasa berinteraksi di bilik guru.

Menurut Mok (2008), guru seharusnya mempunyai sifat dan kualiti peribadi, profesional dan sosial yang baik dan murni. Hanya guru yang mempunyai tatasusila yang tinggi akan berjaya menjalankan tugas sebagai pendidik dengan sempurna, khasnya dalam melaksanakan perancangan penyampaian pengajaran dengan berkesan. Beliau juga menyatakan bahawa seseorang guru perlu mempunyai kualiti profesional yang tinggi seperti ingin tahu, pengetahuan iktisas, suka membaca, kemahiran bertutur, daya ingatan dan daya usaha yang tinggi.

Budaya di tempat kerja memainkan peranan penting dalam pengekalan iklim PdP yang memberangsangkan. Aplikasi Frog VLE memberi satu impak kepada profesionalisme guru di mana penggunaannya dalam PdP mencerminkan keperibadian guru yang tinggi dan sejajar dengan hasrat pendidikan negara. 


\section{IMPLIKASI KAJIAN}

Kajian ini menunjukkan bahawa pelaksanaan Frog VLE masih perlu diperbaiki dan dipertingkatkan. Cadangan seperti adanya pemantauan berterusan daripada pihak pentadbir dan pelan pelaksanaan Frog VLE yang jelas perlu diberikan kepada semua warga sekolah, termasuk ibu bapa. Pihak yang terlibat dalam pembangunan kurikulum pendidikan juga perlu mengurangkan silibus pembelajaran agar guru dapat melaksanakan Frog VLE di dalam bilik darjah secara optimum.

Selain itu, guru juga perlu berfikiran positif dan sentiasa berkeyakinan tinggi untuk menggunakan Frog VLE. Di samping itu, guru juga perlu membuat perancangan pengajaran yang lebih awal supaya dapat memaksimumkan penggunaan Frog VLE dalam PdP. Guru juga perlu bersedia untuk mengikuti kursus yang dianjurkan oleh pihak KPM, JPN, PPD, ataupun Pusat Kegiatan Guru bagi memantapkan lagi ilmu dan kemahiran tentang penggunaan Frog VLE ini. Menurut Siti Aminah (2013), tinjauan awal beliau terhadap penggunaan Frog VLE mendapati bahawa masih ramai guru yang kurang mempunyai kemahiran TMK. Perkara ini bertambah serius apabila ada golongan pentadbir sendiri yang tidak celik TMK dan tidak memberi sokongan kepada guru untuk mengaplikasikan Frog VLE di sekolah. Tanpa sokongan pentadbir, mana mungkin sesuatu program itu akan berjaya, tambahan pula seperti Frog VLE yang memerlukan persiapan dari segi infrastruktur yang lengkap untuk mengendalikannya.

Melalui Frog VLE, guru dapat mewujudkan pendekatan pengajaran dan pembelajaran yang sangat fleksibel. Dengan perancangan yang rapi dan kursus yang menepati keperluan, ianya dapat membantu guru dalam meneroka dan mengaplikasikannya dalam PdP. Guru pasti berkemampuan untuk menghasilkan yang terbaik jika dibantu dan diberi kemudahan serta sokongan oleh semua pihak yang terlibat dalam usaha untuk menjayakannya.

\section{CADANGAN}

Dari perbincangan di atas, beberapa cadangan dikemukakan. Cadangan ini adalah yang berkaitan dengan pelaksanaan Frog VLE bagi memastikan pelaksanaan inovasi ini dapat berjalan dengan lebih lancar dan berkesan di sekolah. Beberapa langkah juga dicadangkan agar pihak kepimpinan sekolah dapat memberikan pertimbangan dalam usaha membangunkan rancangan yang lebih holistik bagi tujuan pelaksanaan Frog VLE ini. Cadangan untuk kajian susulan juga diutarakan. 
Objektif pelaksanaan Frog VLE ini harus jelas, terutamanya kepada pihak pentadbir sekolah itu sendiri. Apabila objektif bagi pelaksanaan inovasi ini jelas, maka ianya akan menjadi lebih mudah bagi pihak pentadbir untuk menyalurkan maklumat kepada pihak yang berkepentingan dalam kalangan komuniti sekolah terutamanya guru, pelajar, dan juga ibu bapa. Matlamat tersebut haruslah boleh digarap, dicapai dan diguna pakai, serta boleh membantu mengatasi apa-apa isu atau masalah berhubung dengan pengajaran dan pembelajaran Frog VLE.

Memandangkan tiga kumpulan sasaran utama bagi Frog VLE ini adalah guru, pelajar dan ibu bapa, rancangan pelaksanaan aktiviti yang melibatkan pihak yang berkepentingan dalam kalangan komuniti sekolah perlu diselaraskan. Pihak pentadbir sekolah boleh memohon jasa baik pihak PPD dan JPN untuk mengadakan satu progam peningkatan kemahiran yang mana program ini akan menjadi satu platform bagi guru, pelajar dan ibu bapa agar dapat saling berinteraksi serta mendapatkan maklumat yang terkini mengenai pelaksanaan inovasi Frog VLE ini.

Perjalanan pelaksanaan sesuatu inovasi itu haruslah dipantau secara konsisten. Pelantikan jawatankuasa yang boleh membantu dalam strategi pemantauan adalah mustahak agak pihak pentadbir mendapat sokongan dan maklum balas dari pihak yang berkepentingan. Maklumbalas berhubung pelaksanaan Frog VLE ini harus dikumpulkan dan dinilai bagi tujuan penambahbaikan. Seterusnya, berdasarkan maklumbalas ini, satu kajian penilaian semula akan dilakukan untuk membaiki strategi pelaksanaan sedia ada.

Peranan pihak pentadbir sekolah adalah penting dalam memastikan kejayaan pelaksanaan Frog VLE ini. Semua pihak memainkan peranan yang penting untuk memastikan pelaksanaan Frog VLE ini dapat dijalankan dengan jayanya agar dapat memberi menafaat kepada semua pihak yang terlibat dalam sistem pendidikan kita, terutamanya pelajar. Ini bertujuan agar dapat melahirkan pelajar yang berilmu, kreatif, kritikal, dan analitikal. Semua pihak haruslah berusaha mengatasi segala cabaran dalam melaksanakan Frog VLE agar inovasi ini dapat dikekalkan demi kepentingan sistem pendidikan di Malaysia.

\section{PENUTUP}

Kesimpulannya, kajian menunjukkan walaupun penggunaan inovasi Frog VLE tidak lagi asing dalam kalangan guru, namun ia masih boleh lagi dikatakan berada di peringkat pengenalan dan agak kurang membantu dalam proses PdP. Pelaksanaan Frog VLE ini masih mempunyai kelemahan yang perlu diatasi supaya dapat membantu dalam kelicinan proses pengajaran dan pembelajaran. 
Beberapa cabaran dan kekangan yang merencatkan pelaksanaan persekitaran pengajaran maya ini di sekolah ini termasuklah kekangan infrastruktur, kekangan masa, efikasi kendiri guru, inisiatif guru, serta integriti dan sikap guru terhadap pelaksanaan Frog VLE. Oleh itu, semua pihak yang berkepentingan seperti pihak pentadbir, guru, pelajar, dan ibu bapa diseru berganding bahu untuk membangun dan meningkatkan penggunaan persekitaran pembelajaran maya secara menyeluruh dalam pelaksanaan Frog VLE di Malaysia.

\section{RUJUKAN}

Al-Bataineh, A. \& Brooks, L. (2003). Challenges, advantages, and disadvantages of instructional technology in the community college classroom. Community College Journal of Research and Practice, 27, 473-484. http://dx.doi.org/ $10.1080 / 713838180$

Albion, P. R. (1999). Self-efficacy beliefs as an indicator of teachers' preparedness for teaching with technology. Chesapeake, VA: Association for the Advancement of Computing in Education (AACE).

Bandura, A. (1977). Self-efficacy: toward a unifying theory of behavioral change. Psychological Review, 84(2), 191-215. http://dx.doi.org/10.1037/0033295X.84.2.191

Bayrei Asrin. (2008). Permasalahan yang dihadapi dalam pengintegrasian teknologi maklumat dalam pengajaran bahasa di sekolah rendah. Unpublished masters thesis, Universiti Pendidikan Sultan Idris.

Dnyaneshwar, S. (2011). Use of virtual classroom in teaching through distance mode: A case study of SCDL. ELT-India. International Journal for the Teachers of English, 1(3), 35-42.

Fadhilah Abtholuddin. (2013). Hubungan antara efikasi kendiri dan kemahiran belajar dalam kalangan pelajar kejuruteraan. Unpublished masters thesis, Universiti Tun Hussein Onn.

Johari Hassan, \& Fazliana Rashid. (2011). Penggunaan ICT dalam proses pengajaran dan pembelajaran di kalangan pendidik Fakulti Pendidikan Universiti Teknologi Malaysia, Skudai, Johor. Journal of Technical, Vocational \& Engineering Education, 4, 22-37.

Kementerian Pendidikan Malaysia. (2012). Laporan awal pelan pembangunan pendidikan Malaysia (2013-2025). Putrajaya: Author.

Loucks, S., Newlove, B., \& Hall, G. (1975). Measuring the level of use of the innovation: A manual for trainers, interviewers, and raters (Report No. 3013). Austin.TX: University of Texas Research and Development Center for Teaching Education.

McKenzie, J. (1999). Reaching the reluctant teacher. From Now On: The Education Technology Journal. Special Summer Issue. Retrieved from http://www.fno.org/sum99/reluctant.html

Mok Soon Sang. (2008). Pedagogi untuk pengajaran dan pembelajaran. Puchong. Selangor: Penerbitan Multimedia Sdn. Bhd. 
Norazila Abdul Aziz. (2008). Taking concerns into account: Understanding the technology adoption process from the ESL teachers' point of view. The English Teacher, 37, 76-89.

Norazilawati Abdullah, Noraini Mohd Noh, Nik Azmah Nik Yusuf, \& Rosnidar Mansor. (2013). Aplikasi persekitaran pengajaran maya (FROF VLE) dalam kalangan Guru Sains. Jurnal Pendidikan Sains \& Matematik Malaysia, 3(2), 63-76.

Posey, G., Burgess, T., Eason, M., \& Jones, Y. (2010). The advantages and disadvantages of the virtual classroom and the role of the teacher. Proceeding Paper, Southwest Decision Institution Conference.

Siti Aminah Khasiman. (2013). Tinjauan awal penggunaan frog VLE di sekolah. Retrieved 7 December 2014 from http://sekolahpenandaaras.wordpress.com

Wan Abdul Rahim, W.I., Nor Laila, M. N., \& Shafie, M. (2006). Toward conceptualization of Islamic user interface for Islamic website: An initial investigation. Proceedings of International Conference on Information, Communications Technology for the Muslim World (ICT4M), Malaysia.

Zarina Mustafa. (2010). Teachers' levels of use in the adoption of task-based language teaching in Malaysian classrooms. The International Journal of Interdisciplinary Social Sciences, 5(3), 127-137. http://dx.doi.org/10.18848/1833-1882/CGP/ v05i03/51621

Zarina Mustafa. (2012). Teachers' encountered challenges in the adoption of task-based language teaching in Malaysian classrooms. The International Journal of Arts and Sciences, 5(3), 269-279. 